\title{
ANILLOS DE CRECIMIENTO EN EL ÁRBOL DE LA CIENCIA La evolución institucional del Consejo Superior de Investigaciones Científicas*
}

\author{
GROWTH RINGS IN THE TREE OF SCIENCE
}

The Institutional Evolution of the Spanish Council for Scientific Research

\author{
Manuel Fernández-Esquinas \\ Instituto de Estudios Sociales Avanzados (IESA-CSIC), Córdoba, España \\ mfernandez@iesa.csic.es
}

Jesús Sebastián

Instituto de Estudios Documentales sobre la Ciencia y la Tecnología, (IEDCYT-CSIC), Madrid,España

jsebastian@cindoc.csic.es

JAVIER LÓPEZ-FACAL

Vicepresidencia de Investigación Científica, CSIC, Madrid, España

J.L.Facal@orgc.csic.es

\section{ENRIQUE TORTOSA-MARTORELL}

Instituto de Gestión de la Innovación y del Conocimiento (Ingenio), CSIC/UPV, Valencia, España

enrique.tortosa@md.ieo.es

\begin{abstract}
RESUMEN
¿Cuáles son los factores que influyen en los modelos organizativos de los grandes centros públicos de investigación de ámbito nacional? ¿Cómo afectan los cambios a la naturaleza de la actividad científica que realizan? Este artículo utiliza el caso del CSIC para estudiar un proceso de cambio organizativo teniendo en cuenta la tensión entre la dependencia del Estado de estos centros y el alto nivel de autonomía de sus comunidades científicas. El principal propósito es explicar cómo la transformación de la estructura de autoridad, junto a la dependencia de agencias de financiación y evaluación, da lugar a la emergencia de las prácticas de investigación consideradas más legítimas y a una reorientación de la actividad científica del conjunto del organismo. Para ello se realiza una narrativa histórica de la situación del CSIC en el periodo comprendido entre la Transición a la Democracia y los inicios del siglo XXI. La narrativa está informada teóricamente por conceptos del enfoque institucional en la sociología de las organizaciones. Los resultados muestran cómo el CSIC se ha convertido en una organización orientada a la ciencia básica. Las conclusiones ofrecen implicaciones para los estudios sociales sobre la ciencia y para las políticas científicas en este campo.
\end{abstract}

\section{Palabras clave Adicionales}

Cambio organizativo, Centros públicos de investigación, Organizaciones cientificas, Política científica. 


\section{SumMARY}

What factors affect the organizational models of the large national public research centers? How does organizational change affect the nature of the scientific activities they perform? This article uses the Spanish Council for Scientific Research (CSIC) to illustrate an institutional change process taking into account the tension that exists between the public status of research centers and the high level of independence of its scientific communities. The main purpose is to explain how changes in the CSIC's internal power structure, along with the relationships with external funding and evaluation agencies, cause those research practices considered most legitimate to emerge and produce a reorientation of the entire organization. To that end, a historical account of the CSIC's situation in the period between the Spanish Democratic Transition and the beginning of the $21^{\text {st }}$ century is provided. The theoretical basis is defined by concepts from new institutionalism in organizational sociology. The results show that during the last quarter of the $20^{\text {th }}$ century, the CSIC has become an organization oriented to basic science. The conclusions have implications for future studies on the transformation of public research centers and for science policy in this field.

\section{Additional KeYWords}

Public research centers, Organizational change, Science organizations, Science policy.

Toda época es una época de transición. Sólo sabemos una cosa del futuro, o mejor, de los futuros: no se parecerán al presente. Jorge Luis Borges

\section{INTRODUCCIÓN ${ }^{1}$}

Los grandes centros públicos de investigación $(\mathrm{CPI})^{2}$ se encuentran, casi por definición, en un permanente estado de transición. El cambio es algo consustancial a cualquier actividad científica. Los desarrollos de las especialidades y la complejidad de las metodologías científicas requieren constantes ajustes organizativos. La manera de entender la ciencia que predomina en cada época influye en la forma de intervención de los Estados y las empresas. Además, estas concepciones son traducidas de diferentes formas en cada contexto nacional, existiendo variaciones que dependen de los resultados que

\footnotetext{
${ }^{1}$ Este trabajo se ha realizado con el apoyo del proyecto de investigación del Plan Nacional de I+D+i "Conocimientos tácitos en la política científica española", Referencia SEJ2006-05025/SOCl. Los autores agradecen sus comentarios a los Dres. Manuel Pérez Yruela, Remo Fernández Carro y Emilio Muñoz Ruiz.

${ }^{2}$ En este artículo se utiliza el término Centros Públicos de Investigación para referirse a los organismos de titularidad pública de carácter no universitario cuyo principal objetivo es la actividad científica. En el caso español se trata principalmente de los llamados OPIs (Organismos Públicos de Investigación) dependientes de la Administración General del Estado y regulados en la "Ley de la Ciencia" de 1986, junto a otros centros de creación más reciente que dependen de las administraciones autonómicas o de fundaciones y consorcios públicos formados por varias administraciones.
} 
se esperan de cada centro en función de las circunstancias políticas y económicas de cada país. No es fácil, por tanto, encontrar una lógica común a la complejidad de situaciones en la nueva oleada de transformaciones que están experimentando los CPI de carácter nacional en las dos últimas décadas (Cox, et al., 2001; EURAB, 2005; Crown y Bozeman, 1998).

El Consejo Superior de Investigaciones Científicas de España (CSIC), cuya imagen corporativa es una representación del árbol bíblico de la ciencia, es un buen exponente de este tipo de cambios. Desde su creación ha experimentado una transición continua que ha dependido de la forma de entender la ciencia dominante en cada época y del contexto político y económico español. Especialmente intensas han sido las transformaciones de los últimos 25 años a raíz de la introducción en España de las políticas científicas modernas y de su incorporación al escenario científico internacional. Este artículo se ocupa de estudiar la evolución del CSIC, centrándose en aquellos procesos de cambio que han supuesto encrucijadas críticas que influyen en la trayectoria que se ha seguido y que sirven para explicar la situación existente en el inicio del siglo XXI.

El CSIC es el mayor organismo de investigación de España con 116 Institutos y 144 Unidades asociadas con universidades y otras instituciones. En el año 2005 trabajan en él 3.200 científicos de plantilla, casi 4.000 becarios pre y postdoctorales y 3.600 personas de apoyo. Tiene un presupuesto de unos 600 millones de Euros. Produce el 19\% de la producción científica española indexada y el $47 \%$ de las patentes internacionales solicitadas por instituciones públicas españolas (CSIC, 2005a). La situación del CSIC es difícil de explicar acudiendo a los enfoques que tratan las tendencias generales de cambio en la ciencia contemporánea. Es cierto que se observan rasgos de la "ciencia postacadémica" (Ziman, 1996), formas de producir conocimientos en el contexto de la aplicación acordes con el llamado "modo 2" (Gibbons, et al., 1994) y que en algunas áreas existen desarrollos tipo "triple hélice" basados en la cooperación con empresas y administraciones públicas (Etzkowitz y Leydersdorff, 2002). No obstante, la evolución del CSIC en su conjunto no se ajusta muy bien a las pautas citadas, al igual que la mayor parte del sistema español de I+D. Desde estos puntos de vista se podría decir, o bien que el CSIC es una especie anómala o, por lo menos, singular, debido a que en muchos de sus institutos la evolución reciente ha sido en sentido contrario a la que apunta la literatura especializada, o bien que los modelos anteriores no dan cuenta cabal de toda la compleja realidad existente.

Este trabajo pretende contribuir a conocer los procesos de transformación de las organizaciones científicas integrando dos perspectivas: la discusión sobre las tendencias en los sistemas de I+D se complementa con las aportaciones de las ciencias sociales que tratan la estabilidad y el cambio en las organizaciones. Más concretamente, se emplea el enfoque del nuevo institucionalismo sociológico (NIS) como marco de análisis que permite orientar la observación de realidades concretas y que aporta explicaciones a las interpretaciones sobre tendencias generales en el mundo de la ciencia. Esta combinación permite explicar evoluciones alternativas y mostrar los mecanismos que intervienen en los cambios. 
La estrategia de análisis utilizada explica la evolución del CSIC acudiendo al desarrollo reciente de la ciencia española. Se estudia la relación entre los llamados factores estructurales (reparto de recursos, distribución de poder y redes de relaciones predominantes) y los factores institucionales (marcos reguladores, normas y pautas culturales que adquieren legitimidad). Para ello se hace hincapié en el desarrollo de distintas culturas de investigación dentro del organismo. Seguidamente se tratan los dos principales procesos de cambio en la historia reciente: la reorganización y democratización de los años 1970 y el impulso político a la I+D de los años 1980. En tercer lugar se exponen las consecuencias de dichos cambios, tanto en lo referido a la evolución de las culturas científicas como en el modelo organizativo que se implanta. Finalmente, se exponen algunos dilemas organizativos recientes y se concluye resaltando algunas implicaciones de la evolución del CSIC para los estudios en este campo y para la política de I+D.

\section{EL CAMBIO INSTITUCIONAL EN LAS ORGANIZACIONES CIENTÍFICAS}

Los cambios en la naturaleza de la ciencia contemporánea que apunta la literatura especializada son bien conocidos. Los principales son: a) aumento del control sobre las inversiones públicas; b) utilización de la ciencia como herramienta de desarrollo económico y social, tanto por los poderes públicos como por el sector productivo; c) emergencia de modelos organizativos híbridos donde coexisten valores y modos de gestión de la academia tradicional y de la empresa (Nowotny, et al., 2003; Martin y Etzkowitz, 2000; Ravetz y Funtowitz, 1993). Aunque parece haber cierto acuerdo en la orientación de los sistemas de I+D, las interpretaciones sobre tendencias generales presentan algunas carencias cuando se trata de observar procesos de cambio en organizaciones concretas. Las principales críticas se han referido a la conocida tesis del "Modo 2". Se suele señalar falta de base empírica suficiente para sostener afirmaciones de carácter general, así como importantes déficits a la hora de especificar los mecanismos causales que explican el cambio (Weingart, 1997). También se alega que este enfoque se utiliza como un soporte normativo que defiende una particular forma de actuación en la ciencia más que como una estrategia de análisis (Godin, 1998). El principal problema proviene de que, a pesar de su popularidad, esta tesis no ha dado lugar a programas de investigación que permitan hacer acumulaciones e ir adaptando las hipótesis a las anomalías que surgen cuando se observan situaciones concretas, algo que sí ocurre en mayor medida en los estudios inspirados en la "triple hélice" (Shinn, 2002).

La combinación del NIS con estas perspectivas proporciona unas herramientas conceptuales y una serie de hipótesis que pueden anclar en mayor medida la observación empírica y aporta algunos elementos explicativos a las tendencias de cambio en los sistemas de I+D identificadas en la literatura. EI NIS suele observar sistemas complejos donde se articulan actividades colectivas (Jepperson, 2002). Es decir, típicamente se ocupa de modos organizativos de la vida social y los trata tanto en su dimensión explí- 
cita (regulaciones y marcos formalizados de acción en estructuras permanentes), como tácita (reglas no escritas que funcionan de manera instrumental y que, además, pueden conformar identidades) (Brinton y Nee, 1998; Searle, 2005). Se asume que estas configuraciones sociales están formadas por una combinación compleja de elementos. Los "pilares institucionales" consisten en elementos cognitivos y culturales, normativos y regulativos, que junto a los recursos económicos y humanos asociadas a ellas, proveen de estabilidad y sentido a la vida social (Scott, 2001). La combinación en diverso grado de estos elementos cognitivos, normativos y regulativos conforman las bases sobre las que descansan las lógicas de funcionamiento de la vida social y la legitimidad referida a distribución de recursos, estatus y poder (Dimaggio y Powell, 1988).

Los estudios realizados desde la perspectiva del NIS han tenido una gran trascendencia en la forma de entender y analizar las organizaciones contemporáneas. Una de sus características esenciales es prestar atención tanto a las llamadas "realizaciones técnicas" como a las "realizaciones institucionales" (Zucker, 1987). La producción de bienes o servicios de acuerdo con los objetivos explícitos de las organizaciones determinan los intercambios económicos con el entorno y, por tanto, afectan a su crecimiento y desarrollo. Sin embargo, existen otros factores igualmente importantes. La conformidad de las organizaciones con expectativas de actores influyentes puede condicionar los intercambios que se realizan. Del mismo modo, el desarrollo o la supervivencia de una organización es algo estrechamente relacionado con la adecuación de sus objetivos a las pautas culturales predominantes, especialmente en el conjunto de organizaciones relacionadas con el mismo sector de actividad de las que se obtienen los recursos, los llamados "campos organizativos". En suma, el desarrollo y crecimiento de las organizaciones normalmente conlleva una conjunción de realizaciones objetivas y de adaptación cultural.

El interés principal de este enfoque se ha centrado en los procesos que generan estabilidad social y resistencia al cambio. El énfasis inicial estaba puesto en los obstáculos al comportamiento de las organizaciones. En particular, en los llamados "efectos institucionales del entorno" que obligan a las organizaciones a actuar de conformidad con las expectativas predominantes en el campo o sector social al que pertenecen (Powell y Dimaggio, 1988). Los estudios recientes han prestado más atención al cambio que a la convergencia (Scott, 2005). Algunas líneas productivas de trabajo muestran la complejidad y la variedad de respuestas organizativas a las regulaciones y las expectativas provenientes del entorno, así como al origen endógeno de los cambios y a la imposición de reglas desde dentro de las propias organizaciones (Colyvas y Powell, 2006). La emergencia de lógicas y marcos cognitivos en competencia dentro de un sector es en ocasiones una fuente de cambio. Por ello, una de las preguntas claves a resolver es si la combinación de elementos coercitivos, regulativos y culturales conduce a comportamientos que están en conformidad con las expectativas y las obligaciones morales, o bien si los miembros de una organización actúan de una determinada manera porque no pueden actuar de una manera diferente (Powell, 2005). En suma, la tarea analítica que ocupa los esfuerzos más recientes en este enfoque está en delimitar los factores que son importantes en contextos particulares 
y hasta qué punto los mecanismos que operan en la configuración de las organizaciones refuerzan el orden social prevaleciente o generan un cambio.

En el ámbito de la ciencia este enfoque se muestra especialmente relevante debido a que, en las organizaciones científicas, existe una especial mezcla de competencias técnicas y elementos simbólicos. Algunos centros de investigación concentran una alta capacidad de producción de resultados susceptibles de tener impacto social y económico. Pero, a la vez, la ciencia es un sistema "altamente institucionalizado" (Drori, et.al. 2003). Las organizaciones científicas tienden a estar estructuradas en torno a la reputación, la credibilidad y el prestigio profesional. Los impactos de muchos productos científicos son difícilmente objetivables y, por tanto, la supervivencia de estas organizaciones depende en gran medida de la legitimidad que adquieren frente a otros organismos del entorno. El intercambio de recursos no está mediatizado únicamente por realizaciones científicas tangibles tales como la trascendencia de los descubrimientos o la resolución de problemas concretos. También está condicionado por factores tales como el estatus de sus miembros o la importancia que se concede a sus objetivos generales independientemente del impacto de sus productos. El uso de este enfoque en las organizaciones científicas representa así una alternativa a las teorías tradicionales de la adaptación que ponían la atención sólo en los bienes tangibles que una organización intercambia con el entorno (Hackett, 2001; Owen-Smith, 2006).

Por otra parte, las organizaciones científicas son culturalmente heterogéneas en lo referido a los objetivos a los que deben orientar su actividad inmediata, así como a los resultados científicos que deben generar (Owen-Smith y Powell, 2001; Dooris y Fairweather, 1994). En cualquier actividad investigadora organizada existen puntos de vista en competencia (Guldbransen, 2000). Una de las tensiones esenciales ocurre entre la orientación a la excelencia científica frente a la orientación a la utilidad inmediata de los resultados de la investigación. Del mismo modo, existen visiones contrapuestas entre la libertad de las comunidades científicas para decidir sus líneas de investigación frente a la coordinación con demandas políticas o económicas. El punto de vista que predomine en una organización científica está estrechamente relacionado con la distribución del poder y la autoridad. Los recursos económicos, el acceso a puestos de trabajo y el reconocimiento profesional se suelen acumular en un sentido u otro de acuerdo con la visión predominante en los colectivos que detentan el poder (Kleinman y Valias, 2001).

En definitiva, los cambios sociales en la ciencia es conveniente analizarlos teniendo en cuenta ambos grupos de elementos. Dada la peculiar naturaleza del trabajo realizado en las organizaciones científicas, los procesos de cambio en este ámbito responden a un especial balance entre realizaciones técnicas y simbólicas. Entender las fuentes y los efectos del cambio en los centros públicos de investigación requiere prestar atención a las reglas, las convenciones y los significados, pero también se debe prestar atención a los mecanismos para la distribución de recursos y a las estructuras de privilegio y desigualdad. El rasgo distintivo del NIS está en identificar los factores que intervienen en los cambios a varios niveles de análisis y en aportar explicaciones de los procesos de estructuración 
social por el que reglas y pautas de actuación se implantan como modelos de actuación predominantes en las organizaciones científicas (Schneider y Clemens, 2006).

Este marco conceptual proporciona unas herramientas de análisis que resultan útiles para iluminar los procesos de cambio en una gran organización científica como el CSIC. Se utiliza para mostrar cómo una alteración en la estructura de poder provoca un proceso de transformación institucional que termina afectando a las funciones y objetivos del conjunto del organismo. La principal hipótesis de partida tiene que ver con las tensiones existentes en los centros públicos de investigación. De un lado, se trata de organizaciones dependientes del Estado en sus objetivos, en la financiación y en la rendición de cuentas. De otro lado, debido al alto grado de especialización, estos centros retienen también un alto nivel de independencia en la ejecución de sus actividades. Los modelos organizativos y la naturaleza de la investigación que se lleva a cabo dependerán de la capacidad del organismo para llevar a cabo una política científica efectiva a través de la asignación de recursos y distribución de recompensas. Dicha capacidad es la que determina si las actividades de investigación consideradas legítimas coinciden con los objetivos formales de la organización, o bien si están influenciadas por otros actores con los que los investigadores interaccionan para obtener recursos y reconocimiento profesional.

En los siguientes puntos se observa la combinación de factores influyentes a lo largo de los últimos 25 años teniendo en cuanta varios niveles de análisis: las comunidades científicas que comprenden el CSIC, la estructura de gobierno y distribución de recursos del organismo, las pautas de relación con las organizaciones del entorno y las actividades políticas y regulaciones en el sistema español de I+D.

\section{LA ETAPA FUNDACIONAL Y LAS LIMITACIONES POLÍTICAS Y ORGANIZATIVAS}

La Ley fundacional del $\mathrm{CSIC}^{3}$ de 1939 le atribuye funciones de primer, segundo y tercer nivel en la ciencia española, es decir, funciones de planificación, de financiación y de ejecución de la investigación en todo el país. Sin embargo, ya en la época inicial existen serias limitaciones para el desempeño simultáneo de estas tres funciones debido al escaso peso político y a la reducida financiación disponible. Pronto surgen desde otros ministerios centros sectoriales y se va produciendo una progresiva especialización del organismo en un ente exclusivamente ejecutor, abandonándose definitivamente las funciones de planificación y financiación. En pocos años el CSIC se convierte sólo en uno de los CPI, el adscrito al Ministerio de Educación y Ciencia (MEC), si bien es el principal

\footnotetext{
${ }^{3}$ La organización inicial del CSIC en 1939 recoge la infraestructura de edificios y laboratorios de la Junta de Ampliación de Estudios e Investigaciones Científicas (JAE), creada en 1907 y disuelta tras la Guerra Civil Española. Sobre la historia de la JAE pueden verse los monográficos de la Revista Arbor n 493 y 499 , realizados en 1987 con motivo del 80 aniversario de su fundación, y el libro dedicado al centenario Tiempos de investigación: JAE-CSIC. Cien años de ciencia en España (Puig-Samper, Ed. 2007).
} 
organismo investigador del país, en el que además se realiza una parte importante de la política científica del Estado.

La organización inicial del CSIC como organismo ejecutor se basa en los patronatos ${ }^{4}$, articulados a su vez en tres grandes subconjuntos: a) las humanidades y ciencias sociales, b) las tecnologías, y c) las ciencias experimentales. Los patronatos adquieren una gran autonomía interna y responden a sistemas de valores y propósitos muy diferentes, con lo que el CSIC en su conjunto tiene un objetivo escasamente definido. El modelo de organización basado en los patronatos da lugar a una separación acusada entre los estilos de trabajo y los procedimientos de gestión de cada uno de ellos. Dentro del CSIC coexisten grandes ramas o subsectores semi-autónomos a los que se atribuye una "misión" distintiva. Una consecuencia de esta división administrativa es el desarrollo de prácticas de trabajo, ideologías profesionales y modos de entender la tarea científica que se pueden considerar como diferentes culturas de investigación. Las culturas más importantes coinciden con los tres grupos de patronatos:

- Las áreas de humanidades y ciencias sociales están dominadas mayoritariamente por catedráticos de universidad, generalmente afectos al régimen franquista, con una fuerte influencia de la religión y de la doctrina oficial de la dictadura. Este hecho influye en las especialidades y contenidos de investigación que más se desarrollan, sobre todo las temáticas consideradas importantes para el régimen, tales como la historia de la etapa imperial, la historia de América y la lengua y filología española. La mayor parte de los profesores utilizan los pequeños institutos como prolongación de sus cátedras y realizan en ellos estudios de contenido monográfico, de marcado carácter individualista y según modelos anteriores a la Guerra Civil.

- Las áreas tecnológicas se integran en el Patronato Juan de la Cierva, cuya misión es realizar investigaciones aplicadas y prestar servicios tecnológicos a la industria. En él se incluyen institutos dedicados a tecnología de los materiales, construcción, minería y tecnologías de alimentos, entre otros. Los institutos de estas áreas se conciben como apoyo a la construcción de una industria nacional organizada según los principios autárquicos de las dictaduras conservadoras de la época. Existe, por tanto, una estrecha vinculación con la industria de propiedad estatal y con los grandes conglomerados industriales. Para algunos sectores se establece un sistema de tasas parafiscales (sobre todo en la minería, el acero y el cemento): un porcentaje de la facturación que las empresas transfieren al CSIC con carácter obligatorio. Estas tasas forman parte relevante de los recursos que reciben los institutos tecnológi-

\footnotetext{
${ }^{4}$ La principal unidad para la ejecución de la actividad científica en el CSIC es el instituto de investigación. Los patronatos son divisiones organizativas que agrupan a institutos de investigación en torno a grandes ramas de la ciencia. En la etapa inicial se establecen seis patronatos, que posteriormente se amplian a ocho. No obstante, en lo referido a la estructura de gobierno del CSIC los patronatos se agrupan en las tres secciones citadas -humanidades, tecnologías y ciencias experimentales-, a las que corresponden las tres vicepresidencias del organismo hasta las reformas de los años 1980.
} 
cos, a cambio de las cuales realizan investigación aplicada y elaboran dictámenes e informes técnicos para la resolución de problemas productivos. Paralelamente, algunas empresas establecen vínculos importantes con los institutos al margen de las imposiciones del Estado ${ }^{5}$.

- Las ciencias experimentales son el tercer gran grupo. Corresponden sobre todo a los institutos de ciencias de la vida y de algunas especialidades de física y química. Desde su fundación suelen tener una mayor conexión con los desarrollos producidos en la ciencia internacional, así como hábitos de trabajo homologables a las comunidades científicas de otros países. La principal misión de estos institutos es incrementar el acervo científico del país contribuyendo al conocimiento de sus respectivas disciplinas. Se trata de centros con una orientación más básica, para los que existe una financiación directa del Estado, aunque en algunos casos también se establecen relaciones con sectores productivos. Por ejemplo, la química se encuentra en una situación intermedia entre las áreas tecnológicas y las experimentales, y posteriormente la biología y biomedicina, con el desarrollo de la biotecnología, ámbito en el también confluyen las áreas de investigación agrícola y tecnología de alimentos. ${ }^{6}$

En las décadas de 1950 y 1960 el CSIC se desarrolla de forma paralela al crecimiento económico del país. Se beneficia especialmente de las inversiones dirigidas a la modernización económica y de las ideas y estilos de trabajo que se incorporan con la primera apertura internacional. Algunas aportaciones provienen de los tratados de cooperación de España con la Alianza del Atlántico Norte y los EEUU. Más adelante, y de manera más relevante, en los años 1960 el CSIC es objeto de importantes inversiones de los llamados "Planes de Desarrollo", que dotan al organismo de una más moderna infraestructura de laboratorios y centros de servicios.

En la década de 1970 el CSIC es ya una gran corporación pública compuesta por 44 institutos propios ${ }^{7}$ y más de 4.500 investigadores y personal de apoyo (ver tabla 1). Es un organismo multidisciplinar que engloba múltiples tareas. Concentra una parte importante de las capacidades científicas del país en la ciencia básica y en

\footnotetext{
${ }^{5}$ El patronato Juan de la Cierva es uno de los más grandes e influyentes debido a los recursos económicos que acumula y al papel estratégico respecto a la industria nacional que le otorga el régimen de Franco. Sobre la historia de este patronato puede verse López García (1999).

${ }^{6}$ Las ciencias agrarias, que constituian un patronato propio, experimentaron una evolución peculiar y algo diferente a las de otras disciplinas y especialidades, lo cual merece un tratamiento específico que no puede tratarse en este artículo. Un análisis de esta área que pone el énfasis en la tecnología de alimentos puede verse en Tortosa (1991).

${ }^{7}$ En el número de institutos se consideran sólo los "institutos propios" y los "institutos mixtos" creados en cooperación con otras entidades. No se incluyen los llamados "centros coordinados con las universidades" debido a la gran variación de su número hasta los años 1980. Todos los datos provienen de las memorias de actividades del CSIC en los años señalados, excepto cuando se indica otra fuente.
} 
algunas especialidades de las humanidades debido a la escasa orientación investigadora de las universidades. También tiene una intensa relación con la industria por dos vías. En primer lugar, por la misión a la que responden algunos de sus grandes institutos. Una característica distintiva de los centros del Patronato Juan de la Cierva es que su actividad consiste en la elaboración de dictámenes, informes técnicos, normas y proyectos conjuntos de investigación. ${ }^{8}$ En segundo lugar, por el desarrollo de relaciones con los sectores industriales emergentes a un nivel más descentralizado en los institutos.

El sistema de financiación de aquellos años es, por tanto, de carácter mixto, aunque con una fuerte coordinación jerárquica en ambas fuentes de ingresos. La mayor parte de los recursos son transferencias directas de los Presupuestos Generales del Estado. Una parte de los recursos externos se obtienen del sector privado por imposición legal, o bien de la industria de propiedad estatal, mientras que otra parte de estos recursos proceden de acuerdos propios del organismo. En los años 1960 y 1970 estos últimos se desarrollan notablemente. Existen numerosos institutos que aprovechan sus capacidades para captar recursos de sectores empresariales al margen de los provenientes del Estado, sobre todo con la gran industria química y con el tejido de pequeñas y medianas empresas en sectores estratégicos de gran crecimiento en aquellos años, principalmente en tecnología de alimentos, agricultura y electrónica.

No obstante, la modernización de los años anteriores a la transición democrática no se refleja de la misma manera en cuestiones organizativas. EI CSIC vino arrastrando importantes problemas derivados de su peculiar situación dentro de la administración pública española. Desde muy pronto se optó por un sistema de carácter burocrático, con investigadores y personal de apoyo con la condición laboral de funcionarios públicos. Al mismo tiempo, se trataba de una administración con un amplio margen de autonomía y discrecionalidad respecto a los poderes del Estado. Los grados de profesionalización y las exigencias de mérito podían variar en función de las relaciones de los directivos de los patronatos e institutos con el régimen de la dictadura. Uno de los presidentes del CSIC en los años de la transición califica a esta situación como un "desgobierno organizado" (Nieto, 1982): una administración pública tradicional que, sin embargo, goza de gran independencia, y que además está dividida en sectores semi-autónomos dispares sobre los que resulta difícil ejercer una coordinación interna o un control externo.

\footnotetext{
${ }^{8}$ Por ejemplo, la actividad de servicios directos a la industria declarada por los centros variaba desde un mínimo del $10 \%$ en los Institutos de Química Orgánica o Automática Industrial hasta más de un $50 \%$ en los Institutos de la Construcción o del Carbón. Ver Patronato Juan de la Cierva (1974).
} 
Tabla 1.

Evolución de los institutos de investigación y los recursos humanos del CSIC

(1970-2005)

\begin{tabular}{lrrrrr}
\hline & 1970 & 1980 & 1990 & 2000 & 2005 \\
\hline Institutos propios & 44 & 56 & 72 & 72 & 76 \\
Institutos mixtos & - & 10 & 21 & 37 & 40 \\
\hline Total & 44 & 66 & 93 & 109 & 116 \\
Personal científico & 1.448 & 1.446 & 1.777 & 2.940 & 3.202 \\
Personal de apoyo & 3.150 & 3.384 & 3.750 & 4.071 & 3.626 \\
Investigadores en formación & - & $* * 372$ & $* 1.618$ & $* 3.781$ & $* 3.802$ \\
Total & 4.595 & 5.502 & 7.145 & 10.792 & 10.630 \\
\hline
\end{tabular}

Fuente: Memorias del CSIC. Años 1970 a 2005. Elaboración propia.

- Datos no disponibles; " Incluye personal predoctoral y posdoctoral; ** Datos de 1981.

\section{Los años SETENTA. Democratización Y CAMBIO SOCIAL EN LA CIENCIA ESPAÑola}

A mediados de los años setenta coinciden en el CSIC tres circunstancias: la reorganización interna, la democratización y la crisis económica. Estos son los principales elementos de una fase de transformación propia de un periodo de cambio social intenso que afecta a toda la sociedad española y que se refleja en prácticamente todas las características del organismo.

En el año 1975 se produce la disolución de los patronatos del CSIC y la transición a la democracia. Ambos procesos coinciden en la misma fecha, aunque no tienen que ver uno con otro. La disolución de los patronatos se promueve desde el equipo del gobierno del organismo con el objeto de paliar las grandes dificultades de control y gestión ${ }^{9}$. Pre-

\footnotetext{
${ }^{9}$ La autonomía de facto de los patronatos hacía extremadamente difícil su coordinación. La variedad de criterios empleada por sus directivos tampoco permitía establecer unos mínimos estándares de calidad científica homogéneos en todos los institutos. Adicionalmente, la crisis del año 1974 hace difícilmente sostenible el crecimiento experimentado en los años anteriores. Las principales razones de la supresión de los patronatos las expresa Eduardo Primo, el presidente que tomó la decisión en aquel momento, en una entrevista a los autores de este trabajo. También se reflejan en su visión personal sobre la transición en el CSIC (Primo Yúfera, 1990). Tras la supresión de los patronatos el CSIC se reorganiza en los llamados "Institutos Nacionales", entidades que intentan una coordinación de los institutos pertenecientes a las mismas especialidades, pero que no llegan a desarrollarse debido a la falta de voluntad de los siguientes presidentes en la etapa de la transición democrática.
} 


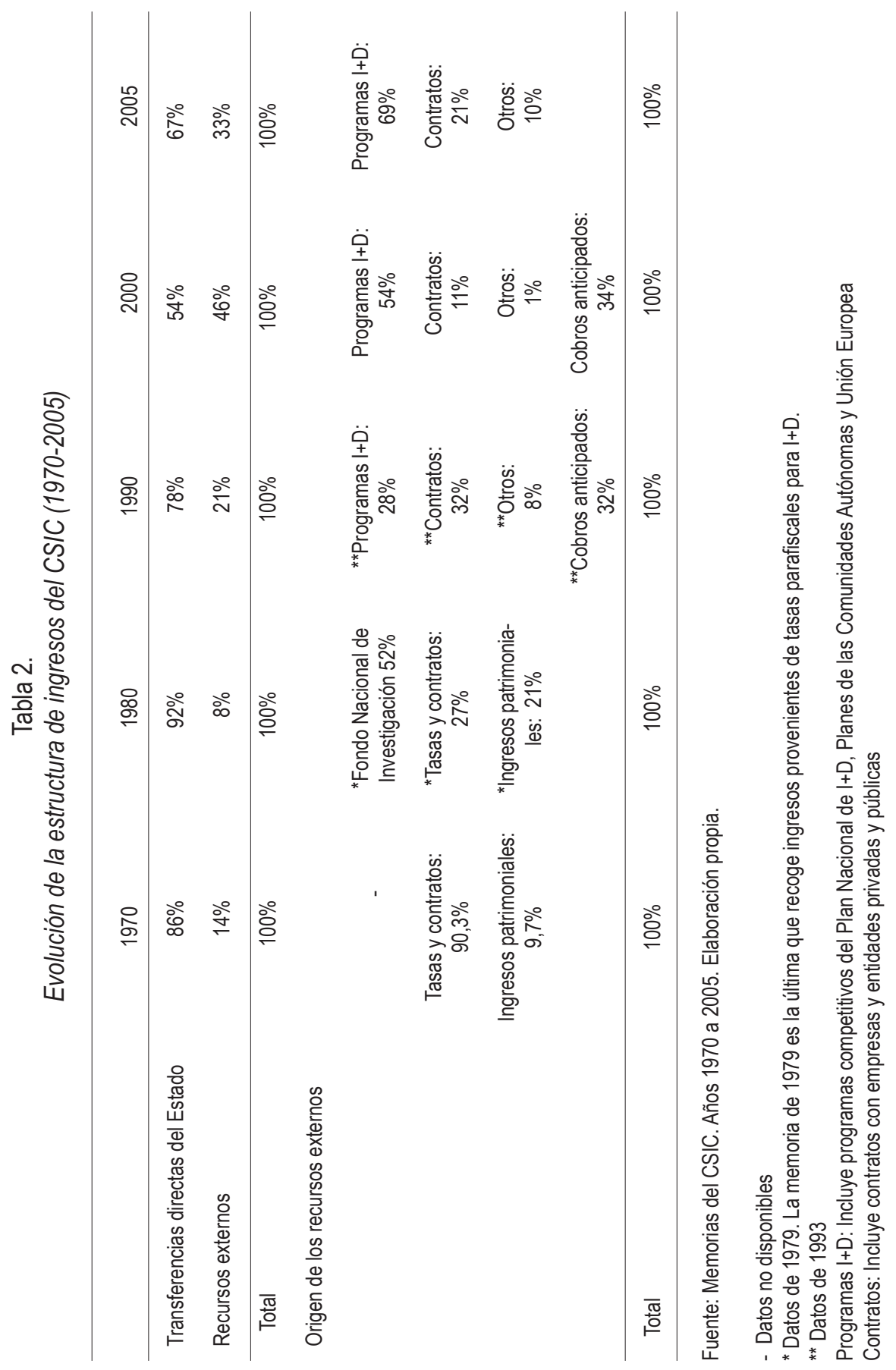


tende sobre todo propiciar un cambio de poder que dé cabida a personas con un perfil investigador más capaz de afrontar los retos científicos que se están produciendo en otros países. Es una de las últimas manifestaciones de la llamada "transición tecnocrática", proceso por el que las elites de poder que ocupan cargos de responsabilidad debido a la adscripción ideológica con el régimen de Franco son sustituidas por directivos más profesionales. En el CSIC esta transición llega con algo más de retraso que en otras partes de la Administración Pública Española debido a su situación de autonomía.

La supresión de los patronatos provoca conflictos entre culturas e intereses debido al nuevo reparto de privilegios y recursos económicos, conflictos que habían permanecido latentes gracias al sistema de gobierno autoritario. Básicamente existe un cambio de poder desde las áreas tecnológicas hacia las áreas de investigación experimental, asociado a que el perfil profesional de las nuevas generaciones que acceden a los puestos de dirección corresponde en mayor medida a las segundas que a las primeras. Paralelamente, la democratización genera un proceso de participación completamente nuevo en un organismo regido hasta ese momento por principios jerárquicos. El Reglamento de funcionamiento interno de 1977 supone un cambio drástico en las formas de distribución del poder. El presidente y el equipo de dirección del organismo siguen siendo nombrados directamente por el Gobierno. Sin embargo, se realiza una gran descentralización de las decisiones a los institutos, llegando a existir en algunos casos experiencias de gestión con rasgos de carácter asambleario ${ }^{10}$. La democratización de la gestión abre una dinámica interna debida a las capacidades que este reglamento permite a los Claustros y Juntas de Instituto. Estos órganos asumen en muchos casos una gran iniciativa, en contraste con la indecisión e inoperatividad de los órganos centrales, lo que acaba siendo determinante en las distintas trayectorias que luego siguen los institutos.

A ello hay que unir la importante crisis económica que sufre España en los años 1970. La crisis fiscal del Estado supone en el CSIC una aguda falta de recursos y un déficit de condiciones laborales y salariales en los trabajadores, especialmente en el personal técnico y en las becas de investigación, que son los colectivos que crecen más en los años de crisis en los que apenas hay ofertas de empleo público. La desaceleración de las actividades productivas y la desaparición de una parte importante del tejido industrial suponen un freno a la colaboración con las empresas y a los ingresos procedentes de este sector, a lo que hay que unir la supresión de las tasas parafiscales. Esta situación económica se refleja claramente en las cifras del año 1980 (tabla 2). Las transferencias directas del Estado pasan a ser el $92 \%$, frente al $86 \%$ del año 1970 . El origen de los recursos externos también sufre una recomposición. Los fondos de las empresas disminuyen notablemente. Los recursos externos dependen más de los ingresos patrimoniales, y empieza a crecer tímidamente el Fondo Nacional de Investigación, que había tenido escaso protagonismo desde su creación en $1964 .^{11}$

\footnotetext{
10 Sobre el impacto del Reglamento de 1977 ver Sebastián y López Facal (2007).

${ }^{11}$ Con el Fondo Nacional de Investigación se introduce en España la primera experiencia de distribución
} 


\section{LOS AÑOS OCHENTA. EL IMPULSO POLÍTICO A LA I+D}

En los años 1980 se produce una reorganización que coincide con un nuevo impulso político a la ciencia española. Los cambios ocurren en varios niveles: en el crecimiento del número de institutos, en la estructura funcional y de gobierno del CSIC y en sus relaciones externas con los organismos que surgen en la nueva configuración del sistema español de I+D.

La llegada al poder del Partido Socialista Obrero Español en 1982 conlleva una serie de cambios legislativos dirigidos a construir una nueva arquitectura institucional para la ciencia española. La llamada "Ley de la Ciencia"12, principal exponente de la reforma, realiza una mejor definición de las entidades políticas, financiadoras y ejecutoras. La piezas más relevantes de la Ley son la dotación estable de un Fondo Nacional para la I+D, la creación de una herramienta de programación y financiación -el Plan Nacional de I+D - y la creación una agencia especializada en la distribución competitiva de los fondos sobre criterios de evaluación por pares - la Agencia Nacional de Evaluación y Prospectiva (ANEP). En el nuevo escenario el CSIC aparece como un actor relevante: se le define como uno de los organismos ejecutores -el mayor de ellos- que deben participar activamente en los nuevos mecanismos de fomento contenidos en el Plan Nacional.

En el interior del CSIC se produce una mayor dotación de fondos a todos los niveles y un crecimiento sustancial del personal investigador gracias a las inversiones públicas. Con el cambio del equipo de gobierno se introducen medidas dirigidas al fortalecimiento de las capacidades de dirección y gestión y a dotar al organismo de mayor visibilidad y protagonismo en el escenario de la ciencia española. Se realiza la simplificación de la red de institutos, suprimiendo y unificando los que tenían menor tamaño. Se elabora una programación de la actividad que se concibe a la vez como instrumento de cohesión interna y como coordinación con las fuentes de financiación externa ${ }^{13}$.

de recursos a la comunidad científica sobre la base de proyectos evaluados por pares. Las mayores innovaciones se producen entre 1975 y 1981 en la llamada CAICYT, que organiza programas temáticos y paneles de expertos inspirados en la National Science Foundation estadounidense. Sobre la implantación en España de los "consejos de investigación" de inspiración anglosajona para la distribución de fondos ver Fernández Carro (2001).

${ }^{12}$ La "Ley de la Ciencia" es la manera abreviada de referirse a la "Ley de Fomento y Coordinación General de la Investigación Científica y Técnica" de 1896, principal iniciativa para la implantación definitiva de la política científica moderna en España. Otros elementos especialmente relevantes de la Ley son la creación de un órgano interministerial de coordinación (CICYT) y la creación de órganos asesores. Los Organismos Públicos de Investigación, entre los que se encuentra el CSIC, se regulan expresamente en la segunda parte de la Ley, considerándose junto a las universidades como los principales destinatarios del Fondo Nacional. Sobre el proceso de construcción de la política científica española en los años 1980 ver Muñoz y Ornia (1987), Sanz (1996), Sebastián y Muñoz (eds.) (2006). Un análisis retrospectivo de la Ley de la Ciencia se contiene en Muñoz y García Arroyo (2006).

${ }^{13}$ En estos años se organiza la coordinación interna en torno a las áreas científicas, que desde ese momento pasan a ser nueve. Ver CSIC (2005). Sobre el proceso de reorganización de los años 1980 ver López Facal, et al., (2006). 
El desarrollo de la Ley de la Ciencia y el ingreso en las entonces llamadas Comunidades Europeas incorporan nuevas lógicas en las relaciones externas del CSIC. EI Plan Nacional de $I+D$, junto al Programa Marco europeo, introducen fuentes de financiación muy diferentes a los mecanismos anteriores. Los patronatos solían recibir asignaciones directas por parte del Estado que transferían a los institutos, y éstos a su vez los distribuían "de arriba abajo" en forma de programas más que en proyectos a corto plazo. En lo referido a los recursos propios de los institutos, especialmente importantes en épocas de crisis, existía un alto control por parte de los directivos tanto en las estrategias de captación como en su asignación a actividades científicas. Por el contrario, las nuevas formas de financiación competitiva se dirigen a los ejecutores finales de la investigación, los científicos individuales articulados en grupos.

La acción política en el CSIC se ejerce, por tanto, en una doble vía. Las medidas acordadas entre el equipo directivo y el MEC se concentran en la construcción de centros, en la dotación de grandes infraestructuras y en la asignación de plazas de personal funcionario. Las herramientas para la financiación de proyectos se dirigen en cambio a la base de la organización, a las comunidades científicas, que se convierten en los principales "clientes" de las políticas científicas. El sistema que acaba predominando es el de la financiación externa. Es más, con el paso del tiempo las actuaciones políticas en la primera vía se dirigen a facilitar la competencia del organismo en la segunda vía. La importancia que adquieren estos mecanismos de financiación provoca la creciente dependencia del CSIC, tanto en los recursos económicos como en la legitimidad de sus funciones, al tener que adaptarse a un sistema basado en las demandas que surgen de las comunidades científicas.

A esta tendencia se añade la escasez de instrumentos financieros y de gestión para que el CSIC lleve a cabo una política científica propia. Las transferencias directas al organismo se dirigen sobre todo a los gastos corrientes, a la dotación de equipamiento científico y al pago de salarios, cuestiones sobre las que existe escaso margen de actuación por parte de los órganos de dirección. Los presupuestos provenientes de la Administración General del Estado ya no permiten realizar una programación de la actividad científica interna. En los periodos de crisis la financiación propia se hace más escasa. La asignación de recursos humanos en régimen de funcionarios, uno de los mecanismos de política científica más efectivos que puede utilizar el CSIC, también disminuye en estos años. Se consolida una forma de actuación que depende de la capacidad de los investigadores individuales para conseguir fondos de las agencias de financiación, donde las lógicas del intercambio se fundamentan en la producción científica indexada y los factores de impacto.

Simultáneamente, crece el interés por establecer una mayor vinculación con el entorno: se crean estructuras de intermediación - la Oficina de Transferencia de Tecnología - que intentan revitalizar las relaciones con la industria. Se trata de promocionar los procesos de transferencia que se han visto mermados en la fase de reorganización del organismo y crisis económica desde la década de 1970. También se trata de realizar un seguimiento de la actividad desempeñada por investigadores individuales e institutos 
y, en la medida de lo posible, de vincular la cooperación que se produce de manera descentralizada con la política general del organismo.

El impulso político en estos años se refleja en un importante crecimiento. En 1990 existen ya 72 institutos propios y 21 institutos mixtos ${ }^{14}$. La plantilla supera a las 7.000 personas, aunque con una importante diferencia respecto a años anteriores: el colectivo que más crece son los investigadores en formación, primero los predoctorales y, más adelante, los posdoctorales. Este crecimiento es resultado de los programas de recursos humanos competitivos procedentes del Plan Nacional de I+D y los planes de los gobiernos autonómicos. EI CSIC se convierte en la organización española que capta más becas de estos programas ${ }^{15}$. Las relaciones directas del organismo con el entorno también experimentan un cambio relevante. Los recursos externos aumentan hasta el $21 \%$, aunque con una estructura muy distinta a la existente antes de los años 1970. En su mayor parte proceden de las agencias de financiación, sobre todo el Plan Nacional y el Programa Marco. También se produce un aumento en los ingresos del sector privado, aunque por vías distintas a las anteriores: los contratos de investigación y las licencias de patentes, frente a los dictámenes y la prestación de servicios técnicos.

\section{LA EVOLUCIÓN DE LAS ÁREAS CIENTÍFICAS FRENTE A LOS CAMBIOS POLÍTICOS Y ORGANIZATIVOS}

El periodo de transición descrito se caracteriza por la desaparición de las transferencias directas para la realización de proyectos de investigación y servicios técnicos, por una creciente autonomía de institutos e investigadores individuales y por un cambio constante en los órganos de dirección, que nunca llegan a llevar a cabo una política científica sostenida. Las únicas entidades organizativas estables con cierta capacidad de acción son los propios institutos de investigación, lo cuál es una fuente de diversidad en las trayectorias que se observan posteriormente. Los cambios políticos y económicos tienen un impacto diferente en las áreas científicas del CSIC debido a la forma en que las comunidades científicas se adaptan a ellos, por lo que es conveniente verlos de forma separada en los tres grandes subconjuntos disciplinarios utilizados antes:

- En lo referido a las humanidades y las ciencias sociales, un punto de inflexión importante es la aparición de personal investigador propio en estas áreas. Desde

\footnotetext{
${ }^{14}$ Los centros mixtos, realizados principalmente en cooperación con las universidades y los gobiernos autonómicos, comienzan a establecerse formalmente en 1986. Con anterioridad existían algunos institutos creados en estrecha cooperación con las universidades, más una cantidad considerable de "unidades coordinadas" (unas 200 en el año 1980), generalmente de muy pequeño tamaño y con escaso personal del CSIC. En su mayor parte fueron suprimidas o integradas en otros institutos. En los años noventa se desarrollan las unidades asociadas con las universidades.

${ }^{15}$ Sobre la política de formación de investigadores en España, incluyendo sus características especificas en el CSIC, ver Fernández Esquinas (2002).
} 
mediados de los años 1970 los investigadores venían asumiendo el protagonismo frente a los profesores de universidad, lo que permitía la profesionalización y la asunción de tareas que requieren continuidad, dedicación y especialización, como es el caso de los grandes proyectos, así como la formación de nuevo personal. Se produce entonces un cierto distanciamiento entre las universidades y el CSIC, aunque se mantienen los flujos de personal y las relaciones más sólidamente establecidas.

A partir de los años 1980 las conexiones con la ideología del régimen desaparecen progresivamente gracias al cambio generacional y a la nueva situación política. Se produce una reorganización drástica de institutos que incluye la supresión de numerosas pequeñas unidades asociadas a las universidades. Se asignan nuevas funciones a los institutos, sobre todo proyectos de investigación de mayor envergadura que requieren personal e infraestructura ${ }^{16}$. También se crean nuevos institutos de ciencias sociales (entre otras, economía, sociología, ciencias políticas y demografía), áreas que hasta entonces habían tenido escaso desarrollo en el CSIC en comparación con las humanidades.

La adaptación de estas áreas a los nuevos sistemas es desigual. Crecen más los institutos que disponen de una misión institucional y aquellos que desarrollan estrategias de crecimiento basadas en explotar la cooperación con otras administraciones. Ambas vías proporcionan recursos que permiten el crecimiento sostenido. El crecimiento es más escaso en los institutos tradicionales que emplean modos de investigación a pequeña escala y en aquellos institutos formados por agregación de investigadores individuales. En estos casos las dificultades provienen de la escasez de los recursos obtenidos de manera competitiva de las agencias de financiación.

- Las áreas tecnológicas son las que experimentan una mayor transformación en la transición al nuevo escenario. Existe una disminución de la presencia de investigadores de estas áreas en los órganos directivos. Las fuentes de financiación cambian debido a la pérdida de las tasas parafiscales y a la disminución de los servicios prestados a las empresas. También se produce una disminución de la relevancia que habían tenido los tecnólogos hasta ese momento.

Un elemento importante de este cambio son las dificultades para adaptarse a los nuevos sistemas de recompensas. En estas áreas existen menos doctores, menos hábitos de publicación y menos dependencia de proyectos captados de manera competitiva. Las formas habituales de trabajo son los programas en torno a grandes problemas tecnológicos y la prestación de servicios de acuerdo con las demandas provenientes de las empresas. También existen menos contactos con la ciencia internacional. Ello provoca que en algunos institutos de gran tamaño se produzca una pérdida de capacidades científicas y un retraso respecto a los desarrollos tecnológicos producidos en otros países e, incluso, respecto a las propias empresas nacionales en algunos sectores.

\footnotetext{
${ }^{16}$ Por ejemplo, los grandes diccionarios clásicos y catálogos lexicográficos. Sobre la elaboración del Diccionario Griego-Español en el CSIC ver Gangutia Elícegui (2007).
} 
En estas áreas la evolución frente a los cambios políticos y organizativos es muy heterogénea debido al impacto del Reglamento de 1977. En todos los institutos de las áreas tecnológicas comienzan a introducirse pautas habituales de los nuevos sistemas de financiación y evaluación. Se produce una reorganización del trabajo en torno a proyectos y se introducen criterios de promoción científica y carreras profesionales basados en publicaciones homologables a la ciencia internacional. No obstante, las estrategias de adaptación y cambio son múltiples: existen institutos que se reconvierten en centros de ciencia básica. Otros buscan nichos de mercado alternativos para la prestación de servicios y la investigación aplicada, mientras que algunos desaparecen o son absorbidos por otros institutos.

- Las ciencias experimentales son, en cambio, las que más se desarrollan en el contexto de las políticas científicas dominantes. Estas áreas ya habían tenido una modernización más rápida que las anteriores, aunque a diferentes velocidades. Había sido más rápida en la física, la química y la biología básica (bioquímica, microbiología, biología molecular y celular), que se internacionalizan a partir de los años 1970. Las ciencias agrarias y naturales se modernizan más lentamente como consecuencia de un menor contacto internacional en la etapa de formación de los investigadores y de las formas de gestión existentes en los patronatos a los que pertenecían los centros de estas disciplinas.

Por su formación científica, por sus hábitos de trabajo y por su grado de internacionalización, las comunidades científicas de estos ámbitos son las que mejor se adaptan al sistema generalizado de financiación de proyectos a través del Plan Nacional de I+D. Se trata de un sistema muy influenciado por los procedimientos de trabajo y la cultura propia de la investigación básica, donde predominan los esquemas de financiación basados en proyectos puntuales formulados de abajo arriba. Adicionalmente, los sistemas de evaluación que se van consolidando, basados fundamentalmente en las publicaciones y sus factores de impacto, también son más afines a estas áreas de investigación. La credibilidad científica y la movilidad profesional basadas en las publicaciones y el reconocimiento por parte de los pares ya estaban incorporadas a su cultura de trabajo prácticamente desde el inicio de los primeros institutos de investigación a comienzos del siglo XX ${ }^{17}$.

En todas las áreas se produce un proceso de convergencia hacia las prácticas de evaluación y presentación de resultados que antes sólo estaban presentes en las ciencias experimentales. También se produce un proceso de convergencia hacia la organización del trabajo en torno a proyectos competitivos a corto plazo. Este proceso de reconversión se refleja claramente en los resultados de la actividad investigadora del

\footnotetext{
${ }_{17}$ Un buen indicador son los dos premios Nobel españoles en disciplinas de ciencias, Santiago Ramón y Cajal (1906) y Severo Ochoa (1959), ambos en biomedicina y vinculados a la JAE.
} 
CSIC (ver tabla 3). En el año 1970 la mayor parte de las publicaciones eran artículos en revistas españolas y los libros y tesis doctorales tenían una importante presencia. Había un número reducido de patentes, aunque importante en comparación con las que existían en el conjunto del país, mientras que los informes técnicos a las empresas ocupaban la mayor parte de las actividades tecnológicas del organismo. En cambio, en el año 1990 la producción científica del CSIC ha cambiado drásticamente su estructura. Las publicaciones científicas en forma de artículos aumentan de una manera exponencial. Las que más crecen son las de carácter indexado en bases de datos internacionales, en detrimento de las nacionales, mientras que la producción de libros y tesis disminuye su importancia en comparación con las anteriores (en 1990 el CSIC tiene el 23\% de la producción española). Las actividades con el entorno también se reconvierten. Desaparecidos casi por completo la gran cantidad de servicios técnicos, comienzan a crecer los contratos, que en su mayor parte son ya proyectos de investigación cooperativa más que dictámenes y servicios de asistencia. También se incrementa la solicitud de patentes, que se multiplica por tres en sólo diez años.

Tabla 3.

Evolución de la actividad científica del CSIC (1970-2005).

\begin{tabular}{|c|c|c|c|c|c|}
\hline & 1970 & 1980 & 1990 & 2000 & 2005 \\
\hline Artículos SCl & - & 510 & 1.321 & 4.442 & 6.720 \\
\hline Artículos no SCl & - & - & - & 1.108 & 1.705 \\
\hline Artículos en revistas extranjeras & 339 & **831 & 2.339 & - & - \\
\hline Artículos en revistas españolas & 1.465 & **2.069 & 1.315 & - & - \\
\hline Libros & 237 & 235 & - & - & 360 \\
\hline Tesis doctorales & 255 & 366 & 564 & 424 & 468 \\
\hline Patentes solicitadas & 19 & **36 & - & 96 & 153 \\
\hline $\begin{array}{l}\text { Informes técnicos a empresas y AA.PP } \\
\text { (1970-1980) } \\
\text { Contratos con empresas y AA.PP } \\
(1990-2005)\end{array}$ & $* * * 6.700$ & *4.357 & 385 & 767 & 1.143 \\
\hline
\end{tabular}

Fuente: Memorias del CSIC. Años 1970 a 2005. Fuente para artículos SCI (Science Citation Index): CINDOC. Elaboración propia. - Datos no disponibles; * Tomado de Nieto, (1982); ${ }^{* \star}$ Datos de 1979. ${ }^{* * \star}$ Cifras de 1972. Estimación a partir de: Patronato Juan de la Cierva (1974). 


\section{LAS CONSECUENCIAS ORGANizAtivas en los años nOVENTA. El ascenso del "MOdelo ESPONTÁNEO"}

Los procesos paralelos citados —reorganización interna, nuevos actores políticos y cambios en los sistemas de financiación- operan como fuerzas centrífugas a partir de los años noventa. Por una parte, se produce una progresiva descentralización de la actividad investigadora del CSIC al depender su financiación de la capacidad de los investigadores individuales para captar recursos fuera del organismo. Las conexiones de los investigadores con los órganos de dirección y coordinación se reducen a la dotación de infraestructuras y puestos de trabajo. Por otra parte, existe una escasa capacidad para hacer política científica institucional. Las unidades administrativas y de planificación apenas crecen en comparación con el aumento de los institutos y del personal científico, lo que hace muy difíciles las actividades de programación o seguimiento. A ello hay que unir los problemas de gestión administrativa que dificultan la capacidad de acción de los órganos de gobierno: los procedimientos contables, la contratación de personal, la coordinación y planificación en la asignación de recursos y la falta de información de las actividades realizadas por los distintos institutos y unidades, limitan notablemente la racionalidad organizativa del organismo.

En este contexto, los mecanismos internos de dirección de la investigación se segregan en varios ámbitos de toma de decisiones. Las áreas científicas se convierten progresivamente en compartimentos semi-autónomos en los que recae una parte importante de la política científica del organismo. Estas tendencias se agravan en la época de crisis económica de los años 1990, cuando los presupuestos públicos para I+D en el conjunto del país sufren una drástica reducción ${ }^{18}$. La crisis se manifiesta en el CSIC con un descenso de las transferencias directas del Estado, lo cual afecta a las herramientas que antes permitían cierta dirección, como son la dotación de puestos de trabajo y la financiación propia de infraestructuras. Ello obliga al organismo a depender en mayor medida de los recursos externos captados por los investigadores, que en el año 2000 llegan al $46 \%$ del total del presupuesto.

Durante este periodo se consolidan varios elementos desvertebradores en el CSIC. Primero, la disminución de los criterios de planificación por objetivos en el Plan Nacional de I+D. Los contenidos de los Planes Nacionales realizados a partir de 1990 no se centran tanto en la programación, cuestión a la que se había dado mayor importancia en la formulación del Primer Plan Nacional vigente entre 1987 y 1990, sino en la distribución del presupuesto en función de las propuestas presentadas por investigadores individua-

${ }^{18}$ Entre 1992 y 1997 los Presupuestos Generales del Estado para I+D, principal fuente financiera del CSIC, sufren un importante retroceso. El porcentaje del PIB en I+D para el conjunto del país en esos años permanece en cifras en torno al 0,8\%. Incluso en 1993 y 1994 desciende respecto a los años anteriores. Sobre la evolución de la inversión en I+D ver Vence y Heijs (2006). Sobre la adaptación del los Organismos Públicos de Investigación españoles a las restricciones presupuestarias de los años 1990 ver Alonso et al. (2001) y Sanz y Cruz (2003). 
les. Segundo, la entrada en escena de las Comunidades Autónomas, que comienzan a establecer políticas científicas regionales, aunque con escasos mecanismos de coordinación con la política del Gobierno del Estado. Se establecen numerosas agencias de financiación que se solapan con la nacional en lo referido a objetivos y herramientas (suelen financiar proyectos y becas, en ambos casos con escasa definición de prioridades temáticas) que engloban entre sus destinatarios a los investigadores del CSIC establecidos en sus territorios ${ }^{19}$. El resultado es que los investigadores del CSIC tienen múltiples fuentes a las que acudir: Plan Nacional de I+D, planes de investigación autonómicos, Programa Marco europeo y otros programas internacionales. Frente a ellos, la única posibilidad de actuación de la dirección del CSIC, habida cuenta de las dificultades para la planificación estratégica, es facilitar que sus investigadores compitan en dichas fuentes.

Estos procesos paralelos tienen como consecuencia la creciente dependencia del entorno y la implantación del llamado "modelo espontáneo" de organización de la investigación (López Facal et al., 2006). Por modelo espontáneo se suele entender una manera de actuación independiente por parte de los institutos y, a su vez, de los investigadores respecto a los institutos. EI CSIC se convierte en una especie de "federación" de institutos, y éstos en una federación de grupos de investigación, lo cual da lugar a una gran diversidad dependiendo de las especialidades y de las culturas predominantes en las comunidades científicas. Otra versión del modelo espontáneo es algo similar al fenómeno de las franquicias comerciales: los nuevos label institutes que surgen bajo el paraguas organizativo del CSIC y se desarrollan buscando su propio nicho de mercado, ya sea público o privado, a partir del margen de actuación que permite el organismo.

El modelo espontáneo citado es sólo un eufemismo para referirse a la ausencia de modelo. No es resultado de un diseño, sino una interpretación a posteriori que se realiza una vez que se han observado los desarrollos ocurridos en varios niveles de la ciencia española. Es algo que emerge como consecuencia de la evolución de los principales organismos ejecutores de investigación (el CSIC y las universidades) y como resultado de los mecanismos de fijación de prioridades y distribución de fondos que predominan en la política científica española. Algo consustancial a la implantación de este modelo es el cambio que se produce en las actividades científicas en el conjunto del CSIC, cuando la agenda de investigación la deciden sobre todo los propios investigadores. En la terminología ya habitual sobre modelos organizativos en la ciencia, se puede decir que en la mayor parte de los centros ocurre una reconversión a las prácticas propias del "Modo 1": se acrecienta la investigación disciplinaria que obtiene legitimidad y se abandonan las actividades de desarrollo tecnológico y prestación de servicios. En lo referido a la relación con las empresas y las administraciones públicas predomina también la iniciativa

\footnotetext{
${ }^{19}$ Varios análisis y reflexiones en torno a la organización de los Planes Nacionales de I+D se contienen en Sebastián y Muñoz, Eds (2006). Sobre las políticas científicas de las comunidades autónomas ver Tortosa (2006), Fernández de Lucio, et al., (2003) y Cruz, et al., (2004).
} 
de los investigadores individuales. En algunas especialidades se produce una gran actividad propia del "Modo 2" gracias a nuevos contratos y a la explotación de patentes. En estas circunstancias es interesante señalar la existencia de algunos institutos híbridos donde coexisten de manera complementaria las prácticas de investigación disciplinarias con la investigación aplicada, aunque siempre sujetas a liderazgos muy concretos de equipos directivos de institutos que incorporan ambas estrategias en su concepción de la investigación ${ }^{20}$.

\section{Una EXPLICACIÓN SOCIOLÓgICA DEL PROCESO dE CAMBIO. PodeR, RECURSOS ECONÓMICOS Y LEGITIMIDAD EN LA CIENCIA PÚBLICA ESPAÑOLA}

La evolución del CSIC es un ejemplo de cómo un cambio en la estructura de poder interna en las organizaciones produce una reorientación en sus objetivos y en los intercambios con otras organizaciones del entorno que termina afectando a la naturaleza de las actividades del organismo en su conjunto. El proceso descrito es una consecuencia no prevista de las políticas científicas que afectan a esta organización. La redistribución del poder y la autoridad van aparejadas a la introducción de nuevas reglas sobre el reparto de recursos. Ello provoca un cambio en las prácticas de investigación que se convierten en mayoritarias, que progresivamente son las que adquieren mayor legitimidad y se terminan asimilando culturalmente.

- En lo referido al cambio de poder en la ciencia pública surge la duda de si las consecuencias son realmente no previstas, o bien si el modelo espontáneo es la forma organizativa buscada por los responsables políticos, habida cuenta de la influencia de los científicos que actúan como policy makers en los años ocheneta y noventa. ${ }^{21}$ En los niveles intermedios de la política científica del Estado, una parte importante de los puestos han sido ocupados por científicos de prestigio procedentes del ámbito académico y de las disciplinas más avanzadas en España de acuerdo con estándares internacionales cercanos a lo que se suele llamar la "republica de la ciencia" (Polanyi, 1962). Se trata de investigadores habituados a emplear activamente sus capacidades y su margen de autonomía en la captación de fondos de manera competitiva, que consiguen alta visibilidad a través de publicaciones y cuya reputación profesional se construye sobre el reconocimiento de los pares. En el caso concreto del CSIC, prácticamente todos los

\footnotetext{
${ }^{20}$ Una explicación detallada del desarrollo de un modelo híbrido en un instituto de química puede verse en Castro y Fernández de Lucio (2007).

${ }^{21}$ El escenario político está influenciado por el marco legislativo del país. Los que redactaron la Constitución Española dejaron plasmado el derecho de la libertad de cátedra, lo cuál, pasados los tiempos de la represión política de la dictadura, se ha interpretado como una garantía de la libertad de elección de líneas de investigación y de modos de organización del trabajo referido a la investigación.
} 
presidentes han procedido de áreas experimentales, al igual que la mayor parte de sus equipos de gobierno. La cultura profesional predominante en los órganos de dirección ha sido la de las ciencias experimentales ya citada.

Con esta acumulación de circunstancias es posible que la cultura profesional de los cuadros directivos haya permeado la forma de hacer política y haya contribuido a que se impongan unas determinadas prácticas. No obstante, es difícil argumentar que el llamado modelo espontáneo haya sido un mero resultado de la toma del poder por parte de los científicos académicos y que éstos hayan sido los que, de manera planeada, hayan implantado modos de funcionamiento más cercanos a sus propios intereses de investigación. Las circunstancias políticas y económicas de diverso orden que ocurren durante la década de los ochenta y noventa, unidas a los comportamientos de las comunidades científicas, obligan a una explicación bastante más compleja. Por ello aquí es preferible interpretar la situación del CSIC como un resultado no previsto de la acumulación de factores, independientemente de que en algunas ocasiones haya influido la cultura profesional y la visión de la ciencia predominante en los equipos responsables de la toma de decisiones.

- Antes de la transición a la democracia en el CSIC existía una situación de autarquía que respondía a una concepción instrumental directa de la investigación. Para ello se disponía de recursos del Estado y de recursos de las empresas privadas muy vinculados a decisiones políticas. Las realizaciones del organismo eran valoradas según los principios de la estructura jerárquica. Después de la transición se produce la adaptación a un sistema de oferta, donde la visión de la investigación ya no tiene un carácter instrumental tan directo. La manera de conseguir una ciencia de calidad, que a su vez tenga posibilidades de tener más impacto económico y social, ya no es dotar a las organizaciones científicas de una misión y unos recursos para llevarla a cabo. Es más bien que las organizaciones y los propios científicos compitan en el exterior sobre la base de la calidad y la relevancia de sus propuestas. Las agencias de financiación y evaluación son los actores principales que orientarán las demandas de los científicos a través de sus ofertas de financiación e incentivos.

Este cambio desde la autarquía hacia el pluralismo del mercado es impulsado por las decisiones políticas que se toman a lo largo de las dos últimas décadas del siglo $X X$. Es parte de la estrategia de democratización y modernización de los gobiernos socialdemócratas, lo cual afecta no sólo al CSIC, sino también a las universidades. En el caso de las universidades, las decisiones de dirigir la financiación a los profesores directamente, y no a las organizaciones, se debe a la falta de confianza en la capacidad de los rectores para canalizar los fondos a actividades científicas frente a las docentes. Los responsables políticos de ese periodo no consideraban factible que las universidades primasen a los colectivos con mayor capacidad para realizar tareas científicas de calidad. Hay que tener en cuenta que, hasta la transición, la Universidad española había tenido un sistema de gobierno autoritario y sus profesores eran reclutados mediante cooptación. La actividad era esencialmente docente y los méritos científicos no eran una 
parte fundamental en el acceso y en las carreras profesionales. Frente a esta situación, el diseño institucional de la nueva política científica se dirige en buena medida a introducir la investigación como parte esencial de las actividades universitarias e incentivar la competitividad de su profesorado. Que los profesores se convirtieran en los principales destinatarios de las agencias de financiación era, por tanto, una de las claves para propiciar un cambio de poder y, a la vez, para que la comunidad académica se convirtiese también en comunidad científica.

EI CSIC se ve afectado por la misma filosofía y por las mismas herramientas de política cientifica pensadas principalmente para las universidades. Esto no se debe tanto a las dudas respecto a la capacidad del organismo de dirigir sus fondos a la investigación de calidad. Se debe más bien a que en el conjunto del CSIC se incorpora la lógica de actuación política que predomina en la administración pública de la que depende: el Ministerio de Educación y Ciencia (MEC). La política científica que se acaba implantando en este ministerio está basada en unos principios de actuación que distinguen escasamente entre la diversidad de algunas organizaciones, como es el caso de gran parte de los institutos tecnológicos del CSIC..$^{22}$ Las medidas de actuación más relevantes, primero la distribución de proyectos y becas de investigación, y posteriormente la evaluación de los currículum científicos, acaban siendo medidas que se imponen a todas las organizaciones dependientes del MEC. Las decisiones políticas puntuales que afectan a la estructura de poder interna del CSIC acaban favoreciendo a aquellos equipos de gobierno más proclives a la implantación de este sistema.

Lo que ocurre en el CSIC es un cambio en la distribución del poder y la autoridad, unido a unas nuevas reglas de juego para el reparto de recursos económicos. Este cambio provoca que se implanten una serie de prácticas e ideas que acaban influyendo en las expectativas y en las funciones de toda la organización. Dentro del organismo ocurre un proceso de democratización y un cambio de los clientelismos propios del régimen anterior por criterios de mérito científico. Fuera del organismo se implantan mecanismos de financiación tipo research councils inspirados en las agencias para apoyar la ciencia básica, que se dirigen sobre todo a individuos. La presidencia del CSIC tiene poca capacidad de dirección y orientación de sus investigadores. La escasa capacidad de dirección se ve favorecida por la autonomía de las comisiones de área y por la libertad de investigación de los funcionarios. Se produce así una falta de autoridad y liderazgo en todos los niveles: a nivel de la presidencia, de las áreas y de los institutos. La orientación profesional de los investigadores deja de ser de carácter "local", definida de acuerdo con los objetivos del organismo, y pasa convertirse en una orientación "cosmopolita" que tiene como referencia a las comunidades científicas externas (Gouldner, 1959).

\footnotetext{
${ }^{22}$ Un desarrollo distinto ocurre en los Organismos Públicos de Investigación sectoriales dependientes de otros ministerios, especialmente del Ministerio de Industria. En estos casos las lógicas de actuación política responden a estrategias de programación dirigidas al conjunto del organismo, encaminadas al cumplimiento de objetivos definidos externamente. Ejemplos relevantes son, entre otros, el CIEMAT (energía), el INTA (investigación aeroespacial) y el IEO (oceanografía). Ver López Facal et. al. (2007).
} 
En esta situación, las prácticas de investigación que tienen más posibilidades de crecimiento son las habituales de lo que antes se ha llamado "cultura de las ciencias experimentales" de mayor velocidad de desarrollo (física, química y biología). El modo de funcionamiento que era más habitual en estas disciplinas, que también eran las más conectadas con la ciencia internacional, ha sido el que se ha trasladado al conjunto del organismo y ha terminado determinando lo que se considera su principal función.

- Los actores principales en el cambio de orientación son las agencias de financiación y evaluación, junto a las comunidades científicas de referencia cuyos miembros más destacados están representados en esas agencias. Los investigadores obtienen recursos y prestigio de estos organismos por un mecanismo de asignación de proyectos en función de la demanda espontánea. No obstante, las agencias externas disponen de escasa capacidad para definir prioridades. El Plan Nacional de I+D y los planes regionales no llegan a disponer de equipos estables que puedan hacer efectiva una planificación por objetivos socioeconómicos. La agencia creada para evaluar la distribución de fondos (ANEP) tampoco se llega a dotar de un aparato organizativo para orientar sus evaluaciones a los objetivos de los planes. Existen dificultades para hacer seguimiento y evaluación ex post. Las únicas evaluaciones posibles son ex ante. A ello hay que sumar la fragmentación de fondos que se agudiza en las épocas de crisis económica de los años noventa. Se financian sobre todo proyectos pequeños y becas de investigación. Las herramientas dirigidas a actividades de envergadura que requieran una participación coordinada de varios grupos de investigación o varias organizaciones se desarrollan escasamente. Frente a la escasa capacidad del Plan Nacional y los planes regionales para establecer objetivos estratégicos en el reparto de fondos, el único criterio posible es el mérito científico. Lo que es factible de ser evaluado es la calidad de las propuestas y la credibilidad del currículum de un investigador para obtener producción científica del proyecto que lleve a cabo.

La escasa capacidad de orientación por parte del CSIC, y la escasa capacidad de establecer prioridades y hacer seguimiento por parte de las agencias para la distribución de fondos, resultan en que el único modelo organizativo posible sea el espontáneo (exceptuando decisiones políticas puntuales que se producen al margen de las agencias externas, sobre todo la creación de centros).

- Este mecanismo provoca que ciertas culturas de investigación adquieran mayor legitimidad que otras. Las prácticas que más posibilidades tienen de imponerse son las de aquellos sectores con más capacidad para obtener recursos. Los investigadores que mejor compiten son los que pueden construir un "ciclo de credibilidad" (Latour y Woolgar, 1982). Es decir, los situados en mejor posición para obtener proyectos y personal de las agencias externas, de convertir esos recursos en producción científica certificada (publicaciones) y de obtener reputación, lo que a su vez facilita el acceso a más recursos y a puestos de trabajo influyentes. A ello contribuye que los puestos con mayor capacidad de decisión en el CSIC y en las agencias de evaluación los ocupan investigadores que comparten este sistema de valores. 
El proceso de cambio de legitimidad se acrecienta a dos niveles. En primer lugar, cuando estas prácticas se formalizan incorporándose a las reglas de funcionamiento oficial y a la distribución de recompensas, como ocurre con el sistema de evaluación de las carreras científicas implantado por una nueva agencia de evaluación: la Comisión Nacional de Evaluación de la Actividad Investigadora (CNEAI) ${ }^{23}$. Las evaluaciones de esta agencia son utilizadas inicialmente como incentivo salarial. Posteriormente, se emplean como requisitos para el acceso a algunos puestos de responsabilidad, como las cátedras universitarias. En segundo lugar, este proceso se arraiga culturalmente cuando las nuevas generaciones de investigadores asumen las nuevas prácticas como pauta cognitiva habitual. La socialización de nuevos científicos se realiza en proyectos obtenidos de manera competitiva y que luego están sujetos a procedimientos de evaluación de los propios pares basados en las publicaciones científicas. Progresivamente este sistema se incorpora como criterio de promoción profesional en las carreras científicas del CSIC. Es entonces cuando los contenidos del trabajo y la orientación profesional hacia las actividades que sean evaluadas positivamente se dan por supuestas en el comportamiento cotidiano de los investigadores.

El proceso citado tiene como consecuencia la orientación del trabajo hacia las expectativas más valoradas, lo cual se refuerza con la sanción positiva de estos comportamientos en términos de promoción profesional y recursos económicos. La actividad investigadora que está asimilada culturalmente como legítima y que, a la vez, es la que mejores resultados materiales obtiene, es la que se dirige a realizar contribuciones al conocimiento público valoradas positivamente por las comunidades científicas de referencia. Esto funciona además como principio para el acceso a puestos de responsabilidad en todos los niveles organizativos: a nivel de grupos de investigación, de la dirección de los institutos y de los órganos de gobierno. Esta es la principal razón de la reconversión del CSIC en un organismo cuya lógica predominante es la producción de conocimientos en forma de publicaciones indexadas, que relega progresivamente las prácticas de colaboración con la industria habituales en las décadas anteriores.

No obstante, conviene hacer alguna matización sobre los casos que no se adaptan completamente a esta pauta. Los motivos para la cooperación con el entorno son muy diversos. Existen grupos de investigadores que escogen la investigación aplicada debido a las dificultades de obtener recursos de las fuentes habituales de la política científica (por ejemplo, en las ciencias sociales y en algunas áreas tecnológicas que no han acumulado suficiente credibilidad para superar las evaluaciones). En otros casos se explotan las oportunidades de mercado que ofrecen los descubrimientos científicos relevantes (por ejemplo, en la biotecnología, en la microelectrónica o en las ciencias

\footnotetext{
${ }^{23}$ La CNEAl se crea en 1989 para aumentar los salarios de los profesores universitarios, en aquel tiempo muy inferiores a los de otros países europeos. El aumento de salarios se realiza a partir de la evaluación de los resultados científicos obtenidos en períodos de seis años. Aunque inicialmente se diseña para el profesorado universitario, el personal científico del CSIC comienza a ser evaluado por esta agencia en el año 1992. Sobre la lógica de funcionamiento de la CNEAI ver Fernández Esquinas, et al. (2006).
} 
químicas). Finalmente, es una práctica generalizada realizar trabajos de investigación aplicada cuya principal motivación es conseguir un complemento económico a los bajos salarios de la administración pública española.

Las actividades de los institutos que han basado su crecimiento en la explotación de oportunidades del entorno han supuesto un importante incremento de los ingresos procedentes de contratos de investigación con empresas y administraciones públicas, al igual que un crecimiento de las patentes. No obstante, éstas son actividades que no suelen proporcionar suficiente legitimidad por sí solas frente a las comunidades científicas de referencia. Más aún, en el conjunto del CSIC estos casos no son el modelo organizativo dominante. Los institutos y los grupos de investigación pueden crecer por la vía de los proyectos competitivos evaluados favorablemente por las agencias de financiación sobre la base de las contribuciones al conocimiento público. Sin embargo, hacerlo sólo por la vía de la aplicación conlleva el riesgo de que los investigadores y los institutos en los que predomina esta orientación se conviertan en divergentes. La tendencia general ha sido, por tanto, el predomino del "Modo 1" en vez del "Modo 2", la ciencia moderna, en vez de la posmoderna, o la "triple hélice" que gira en sentido descendente y que acaba expulsando las demandas provenientes de la empresa o de la administración pública debido a que no se adaptan a las pautas de trabajo habituales del organismo.

\section{DILEMAS ORGANIZATIVOS Y FUNCIONALES EN LA ACTUALIDAD}

Los cambios ocurridos en tres décadas han supuesto una transformación espectacular en el CSIC. Las reformas iniciadas en los años ochenta en el sistema español de ciencia y tecnología han originado indudables avances de amplio reconocimiento. Posteriormente, el CSIC ha crecido al compás del desarrollo económico del país y de los cambios de la administración pública que han afectado al ámbito de la I+D. También ha sido parte activa en la creciente internacionalización de la ciencia española y en la formación y posterior incorporación de nuevas generaciones de personal investigador.

EI CSIC es a comienzos del siglo XXI un organismo de investigación de gran envergadura con una notable diversidad interna. En él conviven diferentes especialidades y prácticas científicas que van desde la ciencia más académica y disciplinaria hasta la investigación organizada en torno a problemas científicos y tecnológicos. En los institutos existen distintos enfoques y lógicas de actuación, desde centros que orientan su actuación a producir conocimientos de frontera hasta institutos híbridos que prestan servicios tecnológicos a la empresa y las administraciones públicas. En su conjunto tiene una notable capacidad para la captación de recursos, tanto en el ámbito público como en el privado. Al mismo tiempo, es el único organismo español de carácter multidisciplinar con una estructura organizativa común y presente en todo el territorio, en el que además se ejecutan algunas de las políticas científicas del Estado. 
Más allá de los indudables avances, la diversidad y heterogeneidad plantean una serie de dilemas que crecientemente se han puesto de manifiesto:

- Un primer dilema proviene de la falta de especificidad de su misión al margen de las formulaciones genéricas de sus estatutos. EI CSIC no tiene unos objetivos claramente identificables, con estrategias institucionales a medio plazo bien priorizadas, más allá de la agregación de acciones en las diferentes áreas e institutos. En la actualidad domina la investigación libre evaluada y financiada externamente en un marco nacional y europeo en el que las políticas científicas priman los instrumentos de financiación frente a los contenidos de la financiación. Desde este punto de vista, el modelo organizativo del CSIC es muy parecido al de la investigación universitaria, si bien con una organización más adaptada a la concentración de sus tareas en la faceta científica.

- Un segundo gran dilema se debe a las dificultades para coordinar y explotar su carácter multisectorial. Por un lado, en la práctica existe escasa relación entre áreas y escasas herramientas organizativas para agregar recursos humanos y materiales en torno a problemas científicos o tecnológicos que estén definidos a niveles distintos a grupos de investigación o científicos individiales. Por otro lado, se producen duplicaciones con las misiones de otros $\mathrm{CPI}$ de carácter sectorial dentro del sistema público de I+D, tales como la investigación biomédica, la investigación agraria, la energía y el medio ambiente o la oceanografía.

- En tercer lugar, un dilema relevante tiene que ver con los mecanismos de gestión. A pesar de ser un organismo muy diverso y con numerosas unidades organizativas muy específicas y distintas entre las diversas especialidades, todas ellas están regidas por reglas e instrumentos comunes. Además, las restricciones de la administración pública española en materia de gestión suponen un importante cuello de botella en el crecimiento. Especialmente importantes son las referidas al personal, donde los procedimientos de selección y contratación y la escasez de incentivos salariales contrastan con un mercado de trabajo cada vez más internacionalizado y con más competencia.

- Y, por último, existen dilemas que son consecuencia de la inserción de un organismo de la Administración General del Estado en un país con una estructura política crecientemente federal. El peso de las Comunidades Autónomas en el fomento de la I+D está adquiriendo un protagonismo notable. Los gobiernos regionales no sólo disponen de sus propios planes de investigación, sino que son cada vez más activos en la creación de centros propios, algunos de ellos en las mismas áreas en que trabajan los institutos del CSIC, con los consiguientes riesgos de solapamiento. 
Durante los años de crecimiento más intenso del CSIC no han surgido respuestas uniformes a estos dilemas. Los inconvenientes de la situación descrita en un contexto como el español se deben a que el modelo espontáneo puede resultar en un gasto que genere escasos retornos económicos y sociales, habida cuenta de que el nivel de inversión en I+D en España es muy inferior al existente en los países europeos más avanzados y depende sobre todo del sector público.

\section{Conclusiones}

El proceso de cambio de una gran organización científica estudiado en este trabajo constituye un caso estratégico que puede contribuir a enriquecer las discusiones sobre las transformaciones de la ciencia contemporánea. Aunque los sistemas nacionales de I+D están experimentando importantes tendencias de cambio, existen notables riesgos a la hora de establecer pautas generales que no estén sustentadas en observaciones empíricas. En unas condiciones dadas es posible que ocurran desarrollos alternativos a los señalados en la literatura especializada, especialmente en organizaciones concretas que están sujetas a las dinámicas de los sistemas de I+D en los que se ubican. Por ello, una estrategia útil en este campo es combinar la discusión sobre el cambio con enfoques como el nuevo institucionalismo sociológico que definen niveles de análisis y permiten establecer mecanismos causales a partir de la observación de factores políticos, económicos y culturales.

El caso del CSIC es un buen ejemplo que muestra cómo la transformación de las organizaciones científicas es un asunto complejo que depende de la articulación de elementos de tipo regulativo, normativo o cognitivo en varios niveles. El cambio experimentado en los últimos años ha sido en sentido contrario al expuesto por las tendencias manifestadas en la literatura. Si hubiese que hacer un resumen sintético del proceso, se podría decir que la evolución ha sido desde el Modo 2 al Modo 1, y que esta evolución no ha resultado en un modelo híbrido, sino más bien en una organización en la que dominan los rasgos de la ciencia básica, a pesar de la existencia de casos destacables de ciencia realizada en el contexto de la aplicación. La explicación aportada muestra un cambio cultural que se ha visto favorecido por el relevo de los colectivos que ocupan el poder político, por la lógica que adoptan los intercambios de recursos con el entorno, y por la legitimidad que adquieren unas prácticas científicas frente a otras.

Del mismo modo, el proceso observado en el CSIC tiene algunas implicaciones relevantes para los estudios sociales sobre la ciencia en varios niveles de análisis. Si nos situamos en el nivel de los sistemas nacionales de ciencia y tecnología, sus características dependerán de las interacciones entre el conjunto de actores que forman el campo organizativo del sector en cuestión. Es decir, de la interrelación entre las organizaciones implicadas en la ciencia, ya sea en la ejecución, en la financiación o en la regulación, así como de los marcos normativos predominantes. Aquellos sistemas en los que la distribu- 
ción de recursos y estatus se realiza de acuerdo con los principios de autogobierno de la ciencia académica, y donde además existen regulaciones en el mismo sentido, tienden a generar homogeneidad en las prácticas y en las pautas culturales que se acaban imponiendo en el conjunto.

En el nivel de las organizaciones científicas, los desarrollos dependen de los factores que intervienen en los intercambios que se realizan con el entorno. En actividades altamente institucionalizadas como la investigación, cuyos resultados no son fácilmente traducibles a elementos tangibles, los intercambios organizativos no son sólo un asunto del impacto social y económico de la I+D. Dependen de la legitimidad que tengan sus objetivos y resultados en el entorno. Los recursos se suelen acumular en aquellas prácticas de trabajo que son consideradas más legítimas por los colectivos que tienen poder y autoridad en aquellas organizaciones de las que dependen los intercambios.

Finalmente, también es posible obtener implicaciones para las políticas científicas debido a que las intervenciones en la I+D pueden tener consecuencias no previstas. Los resultados de las políticas en este campo dependen del comportamiento de las comunidades científicas en relación con los sistemas de incentivos. Las políticas basadas sólo en la oferta dan lugar a modelos organizativos sustentados en el autogobierno de las comunidades científicas, que tienden a estructurase en torno a la excelencia. Es decir, los grupos que acumulan estatus y recursos sobre la base de las publicaciones reconocidas por los pares de cada área son los que se convierten en referencia de la competencia profesional. Las actuaciones basadas sólo en la excelencia son un motor para producir conocimientos certificados. No obstante, también son la otra cara de la moneda del conocido modelo lineal de la I+D en las políticas de ciencia y tecnología.

\section{REFERENCIAS BIBLIOGRÁFICAS}

Alonso, S., Fernández, J. R. y Sanz, L. (2001), "Spanish public research centres' responses to changes: diversification of funding resources", en D. Cox, P. Gummett y K. Barker (Eds.): Government Laboratories: Transition and Transformation, Amsterdam: IOS Press, 2001.

Bozeman, B. y Crow, M. (1990), "The environments of US R\&D laboratories: political and market influences", Policy Sciences 23: 25-56.

Brinton, M. C. y Nee, V. (1998), The new institutionalism in sociology, Stanford, CA: Stanford University Press.

Castro Martínez, E. y Fernández de Lucio, I. (2007), "Iniciativas institucionales e individuales en la creación de estructuras científicas: el caso del Instituto de Tecnología Química”, Arbor 727: 803-819.

CICYT (2007), Estrategia Nacional de Ciencia y Tecnología, Madrid: Fundación Española para la Ciencia y la Tecnología.

CSIC (2005a), Memoria de Actividades 2005, Madrid: Consejo Superior de Investigaciones Científicas. 
(2005b), Plan de Actuación 2006-2009, Madrid: Consejo Superior de Investigaciones Científicas.

Colyvas, J. y Powell, W. (2006), "Roads to Institutionalization: The Remaking of Boundaries Between Public and Private Sciences", Research in Organizational Behavior 21: 305-53.

Cox, D., Gummett, P. y Baker, H. (eds.) (2001), Government laboratories: transitions and transformations, Amsterdam: IOS Press.

Crow, M. y Bozeman, B. (1998), Limited by design. R\&D laboratories in the US Innovation System, Nueva York: Columbia University Press.

Cruz, L., Sanz, L. y Romero, M. (2004), "Convergencia y divergencia en las políticas de ciencia y tecnología de los gobiernos regionales", Revista Española de Ciencia Política 11: 31-70.

Drori, G., Meyer, J., Ramírez, F. y Schofer, E. (2003), Science in the modern world: institutionalization and globalization, Stanford: Stanford University Press.

Etzkowitz, H. y Leydesdorff, L. (2000), "The dynamics of innovation: from National Systems and "Mode 2" to a Triple Helix of university-industry-government", Research Policy 29 (2): 109-123.

DiMaggio, P. J. y Powell, W. W. (1983), "The iron cage revisited: Institutional isomorphism and collective rationality in organizational fields", American Sociological Review 48: 147-160.

(1991), The new institutionalism in organizational analysis, Chicago: University of Chicago Press.

Dooris, M.J. y Fairweather, J.S. (1994), "Structure and culture in faculty work: implications for technology transfer", The Review of Higher Education 17-2: 161-177.

EURAB-European Research Advisory Board (2005), Research and Technology Organisations (RTOS) and ERA, Final report EURAB 05.037, December 2005.

Fernández Carro, R. (2001), Regímenes políticos y actividad científica, Madrid: Fundación Juan March.

Fernández de Lucio, I., Rojo de la Viesca, J. y Castro Martínez, E. (2003), Enfoque de Políticas Regionales de innovación en la Unión Europea, Madrid: Academia Europea de Ciencias y Artes. Delegación Española.

Fernández Esquinas, M. (2002), La formación de investigadores científicos en España, Madrid: Centro de Investigaciones Sociológicas.

Fernández Esquinas, M., Pérez Yruela, M. y Merchán Hernández, C. (2006), "El sistema de incentivos y recompensas en la ciencia pública española", en Sebastián, J. y Muñoz. E. (Coords.): Radiografía de la Investigación Pública en España, Madrid: Biblioteca Nueva.

Funtowitz, S. y Ravetz, J. (1993), "The emergence of postnormal science", en Von Schomberg, R. (ed.): Science, Politics and Morality: Scientific uncertainty and decision making, Dordrecht: Kluwer.

Gangutia Elícegui, E. (2007), "El Diccionario Griego-Español”, Arbor 727: 749-769.

Gibbons, M. et al., (1994), The new production of Knowledge, Londres: Sage.

Godin, B. (1998), "Writting performative history: the New Atlantis?", Social Studies of Science 28: 465-483. 
Gouldner, A. (1959), "Cosmopolitans and locals: toward an analysis of latent social roles", Administrative Science Quarterly 2: 281-306.

Guldbransen, M. (2000), "Between Scylla and Charybdis -and enjoying it?: Organizational tensions and research work", Science Studies 13 (2): 52-76.

Hackett, E. (2001), "Science as a vocation in the 1990's: the changing organizational culture of academic science", en Croissant, J. y Restivo, S. (Eds.): Degrees of compromise. Industrial interests and academic values, New York: SUNY Press.

INE (2005), Estadística de Investigación Científica y Desarrollo Tecnológico, Madrid: Instituto Nacional de Estadística.

Jang, Y. (2000), "The worldwide funding of ministries of science and technology", 1950-1900, Sociological Perspectives 43 (2): 247-270.

Jepperson, R. (2002), "The Development and Application of Sociological Neoinstitutionalism", en Berger, J. y Zelditch, M. (Eds.): New Directions in Contemporary Sociological Theory, Nueva York: Rowman \& Littlefield.

Kleinman, D. y Valias, S. (2001), "Science, capitalism and the rise of 'knowledge worker': The changing structure of knowledge production in the United States", Theory and Society 30 (4): 451-492.

Latour, B. y Woolgar, S. (1982), La construcción de los hechos científicos, Madrid: Alianza Editorial.

López García, S. (1999), “El Patronato Juan de la Cierva (1939-1960). III Parte”, Arbor 637: 1-32.

López Facal, J., Ugalde, U., Zapata, A. y Sebastián, J. (2006), "Dinámica de la política científica española y evolución de los actores institucionales", en Sebastián, J. y Muñoz. E. (Coords.): Radiografía de la Investigación Pública en España, Madrid: Biblioteca Nueva.

Martin, B. y Etzkowitz, H. (2000), "The origin and evolution of the university species", VEST 13 (3-4): 9-34.

Moore, K. (1996), "Organizing integrity: American Science and the creation of Public Interest Organizations", 1955-1975, American Journal of Sociology 101 (6): 1592-1627.

Muñoz, E. y García Arroyo, A. (2006), "El nacimiento de la Ley de la Ciencia: el sueño del progreso", Revista Madritd, Diciembre de 2006: 21-25.

Muñoz, E, y Ornia, F. (1987), Ciencia y Tecnología: una oportunidad para España, Madrid: Aguilar

Nieto, A. (Ed.) (1982), Apuntes para una política cientifica, Madrid: Consejo Superior de Investigaciones Científicas.

Nowotny, H., Scott, P. y Gibbons, M. (2003), "Introduction: 'Mode 2' Revisited: The New Production of Knowledge", Minerva 41, 3: 179-194.

Owen-Smith, J. (2007), "Structural components of institutional change: the shifting field of play for science and commerce in academe", mimeo. 
Owen-Smith, J. y Powell, W. (2001), "Careers and contradictions: faculty responses to the transformation of of knowledge and its uses in the life sciences", in Research in the Sociology of Work 10: 109-140.

Patronato Juan de la Cierva (1974), Criterios para la Planificación y Programación de Actividades, Madrid: CSIC.

Polanyi, M. (1962), "The Republic of science: Its political and economic theory", Minerva, 1: 54-73.

Porter, K., Bunker, K. y Powell. W. (2005), The Institutional Embeddedness of High-Tech Regions, in S. Breschi and F. Malerba (Eds.): Clusters, Networks, and Innovation. Oxford University Press.

Powell, W. (2007), "The New Institutionalism", en The International Encyclopedia of Organization Studies, Thousand Oaks, CA: Sage Publishers.

Powell, W., Koput, K. y Smith-Doerr, L. (1996), "Inteorganizational collaboration and the locus of innovation: networks of learning in biotechnology", Administrative Science Quarterly 41: 116-145.

Primo Yúfera, E. (1990), "Transición en el CSIC”, Arbor 529: 49-60.

Puig-Samper, M. A. (Coord.) (2007), Tiempos de Investigación. JAE-CSIC: 100 Años de Ciencia en España, Madrid: Consejo Superior de Investigaciones Científicas.

Sanz, L. (1996), Estado, ciencia y tecnología en España, Madrid: Alianza.

Sanz, L. y Cruz, L. (2003), "Coping with environmental pressures: public research organizations responses to funding crisis", Research Policy 32 (8): 1293-1308.

Scott, R. (2001), Institutions and organizations (Second edition), Thousand Oaks, CA: Sage.

(2005), "Institutional theory: contributing to a theoretical research program", en Smith, K. y Hitt, M. (Eds.): Greats minds in management: The process of theory development, Oxford: Oxford University Press.

Searle, J. (2005), "What is an Institution?", Journal of Institutional Economics 1(1): 1-22.

Sebastián, J. y López Facal, J. (2007), "Transición y cambio en el CSIC", en Puig-Samper, M. A. (coords.) op. cit.

Sebastián, J. y Muñoz. E. (Coords.) (2006), Radiografía de la Investigación Pública en España, Madrid: Biblioteca Nueva.

Shinn, T. (2002), "The Triple Helix and New Production of Knowledge: Prepackaged Thinking on Science and Technology", Social Studies of Science 8, Vol. 32: 599 - 614.

Schneider, M. y Clemens, E. (2006), "The typical tools for the job: Research strategies in institutional analysis", Sociological Theory, №. 24, pp. 195-227.

Tortosa, E. (1991), "La tecnología de alimentos”, en López Piñero, L. (Ed): España: Ciencia, Madrid: Espasa.

(2006), "La I+D en el marco autonómico", en Sebastián, J. y Muñoz. E. (coords.) op. cit. 
Vence, J. y J. Heijs (2006), "Estructura y flujos de la financiación de la I+D en España", en Sebastián, J. y Muñoz. E. (Coords.) op.cit.

Weingart, P. (1997), "From 'finalization' to 'Mode 2': old wine in new bottles?", Social Science Information 36: 591-613.

Weingart, P., Krücken, G. y Hasse, R. (1997), "Ciencia y entorno social: una aplicación del enfoque neoinstitucionalista a los estudios sociales de la ciencia", Revista Internacional de Sociología 16: 117-137.

Ziman, J. (1996), "Postacademic science: constructing knowledge with networks and norms", Science Studies, $\mathrm{N}^{0} 9$.

Zucker, L. (1987), "Institutional Theories of Organization", Annual Review of Sociology 13: 443-464.

RECIBIDO: $17 / 07 / 07$

ACEPTADO: 26/06/08 